\title{
Evaluation of the Masticatory Efficiency Pre- and Post-Periodontal Treatment in Patients with Periodontitis in South Indian Population
}

\author{
Sangeetha Shankar ${ }^{1}$, Thamaraiselvan Murugan² \\ ${ }^{1}$ Department of Periodontics and Implantology, Saveetha Dental College \& Hospitals, Saveetha \\ Institute of Medical and Technical Sciences, Velappanchavadi, Tamilnadu, India. ${ }^{2}$ Department of \\ Periodontics and Implantology, Saveetha Dental College \& Hospitals, Saveetha Institute of Medical \\ and Technical Sciences, Velappanchavadi, Tamilnadu, India.
}

\section{ABSTRACT}

\section{BACKGROUND}

Mastication is the very first step in digestion which facilitates digestion by grinding the food. Masticatory efficiency is regulated by a variety of factors such as health status of periodontium, occlusal contacts, oral musculature and bite force.

\section{METHODS}

A controlled parallel design interventional study was conducted. A total of 40 subjects (40-70 years) attending the Out-Patient Department of Saveetha Dental College and Hospitals, (SIMATS), Chennai, were recruited for the study. Group A or Test group consisted of patients with chronic periodontitis and Group B or Control group had patients with healthy periodontium. Using pre-weighted chewing gum which tend to change colour on mastication, Test and Control groups were asked to masticate for 20 chewing cycles. The chewing gums were then weighed again using the laboratory analytical balance. The above procedure was carried over at baseline, immediate, 1-week and 1-month post-periodontal therapy for every patient belonging to the Test group. The periodontal therapies that were performed were scaling, root planing and flap surgery. The masticatory efficiency was evaluated by comparing the mass of the chewing gum between the Test group and Control group and between each interval within the test group.

\section{RESULTS}

The results were calculated statistically using paired t-test. The weight of the chewing gum in Group A at baseline, post 1 week, post 1 month were $1.41 \pm 0.23$ gms, $0.94 \pm 0.43$ gms and $0.46 \pm 0.35$ gms respectively and the control group is $1.1615 \pm 0.36$ gms.

\section{CONCLUSIONS}

Within the limitations of the study, we conclude that the masticatory efficacy of patients with periodontitis i.e. those with reduced periodontal tissue support is reduced and did not improve even after periodontal therapy.

\section{KEY WORDS}

Periodontitis, Masticatory Efficiency, Periodontal Therapy
Corresponding Author: Department of Periodontics, Saveetha Dental College \& Hospitals, Saveetha Institute of Medical \& Technical Sciences,

162, Poonamalle High Road, Velappanchavadi, Chennai - 77.

E-mail: thamaraiselvan2001@gmail.com

DOI: $10.14260 /$ jemds/2020/142

Financial or Other Competing Interests: None.

How to Cite This Article:

Shankar S, Murugan T. Evaluation of the masticatory efficiency pre and post periodontal treatment in patients with periodontitis in South Indian population. J. Evolution Med. Dent. Sci. 2020;9(09):651654, DOI: 10.14260/jemds/2020/142

Submission 17-12-2019,

Peer Review 05-02-2020,

Acceptance 11-02-2020,

Published 02-03-2020.

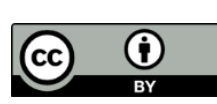




\section{BACKGROUND}

Mastication or chewing is defined as a mechanical process by which food is broken down into smaller particles thus helping in swallowing and digestion. It is the very first step in digestion. ${ }^{1-3}$ To lead a healthy life, proper nutrition is important which is primarily facilitated by proper mastication or in other words-proper chewing. The term masticatory performance can be defined as the ability to grind certain portion of food with determined number of masticatory cycles, while the term masticatory efficiency is related to the amount of chewing necessary to achieve a given degree of grinding of test food, independently of the number of masticatory cycles. $4,5,6$

Masticatory efficiency is regulated by a variety of factors such as healthy status of periodontium, occlusal contacts, oral musculature and bite force. With respect to occlusal contacts, some studies suggest that masticatory efficiency is determined primarily by the number and size of occlusal contacts. This is because it is the contacts between the occluding teeth that determine the area available for grinding food during each masticatory cycle. ${ }^{7-12}$ Studies conducted by Van der Bilt et al,13 Omar et al,14 Luke and Lukas ${ }^{15}$ and Wilding 10 reported significant relationship between occlusal contact area and masticatory efficiency. Bite force is used to determine the functional state of masticatory system.7,16 It is one of the contributing factors for normal mastication and is regulated by physiological factors such as craniofacial morphology, alignment of teeth, age, gender, temporomandibular disorders. ${ }^{8}$ In relation to periodontium, the forces generated during mastication which is carried out with the help of masticatory muscles are controlled largely by the mechanoreceptors present in the periodontium (periodontal ligament and the alveolar bone).6,17,18,10 A hypothesis suggests that the threshold value of the mechanoreceptors present in the periodontium is lower in teeth with reduced periodontal tissue support when compared to that of the ones with normal periodontal support.6,11

There is inadequate literature evidence regarding the influence of periodontal health status on the masticatory efficiency. In addition, it is evident that periodontal therapy results in regeneration or reconstruction of periodontium, 19 but what is lacking is, whether this facilitates improved masticatory efficiency. Hence this study was designed with an aim to evaluate and compare the masticatory efficiency of individuals with healthy periodontium and periodontally diseased individuals also whether periodontal therapy improves the masticatory efficiency in periodontally diseased individuals in South Indian population.

\section{METHODS}

A controlled parallel design interventional study was conducted. The sample size calculation using $\mathrm{G}$ power software showed a total of 36 (18 in each group) subjects were required for the study. Considering the dropouts, a total of total of 40 subjects (20 in each) aging 40-70 years including 28 females and 12 males attending the Out-Patient Department of Saveetha Dental College and Hospitals,
(SIMATS), Chennai, who satisfied the inclusion and exclusion criteria were recruited for the study. Institutional Ethical Committee approval was obtained. The procedures were explained to patients and written informed consent was obtained.

The study consisted of groups - Group A or Test group (subjects with chronic periodontitis) and Group B or Control group (subjects with healthy periodontium). The inclusion criteria for Group A are subjects with presence of Periodontal probing depth $(>5 \mathrm{~mm})$, loss of attachment $(>2 \mathrm{~mm})$, tooth mobility (grade I and II), ${ }^{20}$ plaque score (PI > $20 \%$ ), with no missing teeth or malocclusion such as severe crowding or pathological migration. Patients with any of the following were excluded: teeth which has hopeless prognosis, those who underwent periodontal therapy recently, those with multiple missing posterior teeth, physically or mentally disabled patients, systemic or genetic disorders, pathologies affecting oral musculature, systemic illness known to affect the outcome of periodontal therapy, use of tobacco or alcohol, patients with restorations or caries in the posterior region (molar region).

For the study, mint flavoured, liquid filled chewing gum which tend to change colour on mastication was used. The chewing gums were weighed prior to the study using a laboratory analytical balance in the Biochemistry Department of Saveetha Dental College and Hospital, (SIMATS), Chennai. Participants of the Test and Control groups were asked to chew the pre-weighed gums for 20 chewing cycles. Then these were dehydrated and weighed again using the laboratory analytical balance. The above procedure was carried over at baseline, immediate, 1 week and 1 month post- periodontal therapy for every patient belonging to the Test group, and only at baseline in the control group. The periodontal therapies that were performed were scaling, root planing, flap surgery.

\section{Statistical Analysis}

The statistical analysis was done with SPSS software. The mean weight of the chewing gums, between the groups were compared with independent Student ' $t$ ' test, and within test group (Group A) using paired ' $t$ ' test.

\section{RESULTS}

The results showed no statistically significant difference ( $p$ value $<0.05$ ) in weight of the chewing gums when compared between the groups at baseline (table 1) but when compared within test group (group A) pre and post periodontal therapy, there was no statistically significant different ( $p$ value $>0.05$ ) (table 1).

\begin{tabular}{|c|c|c|c|c|c|}
\hline \multirow{2}{*}{$\begin{array}{c}\text { Sl. } \\
\text { No. }\end{array}$} & Title & $\begin{array}{c}\text { Baseline } \\
\text { (Grams) }\end{array}$ & $\begin{array}{c}\text { Post-1 Week } \\
\text { (Grams) }\end{array}$ & $\begin{array}{c}\text { Post- 1 Month } \\
\text { (Grams) }\end{array}$ & $\begin{array}{c}\text { Baseline } \\
\text { (Grams) }\end{array}$ \\
\hline 1. & $\begin{array}{l}\text { Weight of the } \\
\text { chewing gum }\end{array}$ & $1.41 \pm 0.23$ & $0.94 \pm 0.43$ & $0.46 \pm 0.35$ & $\begin{array}{c}1.1615 \pm \\
0.36^{*}\end{array}$ \\
\hline \multicolumn{6}{|c|}{$\begin{array}{r}\text { Table 1. Comparative Tabular Representation of } \\
\text { Mean Values of Weight of the Chewing Gum }\end{array}$} \\
\hline \multicolumn{6}{|c|}{ *Statistically significant at Baseline between groups (p value < 0.05) } \\
\hline
\end{tabular}




\section{DISCUSSION}

Masticatory efficacy can be assessed by many methods and one among them is the use of pre weighted chewing gums. The weight reduction after chewing corresponded to the amount of sugar that was lost, indicating the masticatory efficiency. The results from our study revealed that the baseline values with respect to the weight of the chewing gum in the Test and Control group varied to a great extent with the healthy group (group B) showing more efficiency (table 1). Similar results were observed in a study by Kleinfelder et $\mathrm{al}^{6}{ }^{6}$ who assessed the maximal bite force in patients with reduced periodontal tissue support with and without splinting where the preoperative values were found to be $378 \mathrm{~N}$ and $357 \mathrm{~N}$ in Control and Test group respectively. The difference in masticatory efficacy between the two groups maybe due to a lot of factors such as loss of proprioception, periodontal tissue destruction, the threshold value of the mechanoreceptors presents in the periodontal tissues, etc. In our study, the values post 1 week and 1 month in Test Group were $0.94 \pm 0.4$ grams and $0.46 \pm 0.3$ grams respectively. This shows the masticatory efficacy is reduced after periodontal therapy. This is in contradiction to those reported by Laurell et al ${ }^{21}$ and Kleinfelder et al, 6 who found a significant improvement in the biting force after periodontal therapy in the Test Group.

The reduction in the masticatory efficacy of the Group A (test group) patients after periodontal therapy appears to be redundant but it could be possibly due to the following reasons. The time of evaluation of masticatory efficacy after periodontal therapy like flap surgery might have played a crucial role. In the studies reported by Laurell et.al ${ }^{22}$ and Kleinfelder et $\mathrm{al}^{6}{ }^{6}$ an improvement was observed after splinting rather than surgical therapy in the Test Group. In the present study the periodontal therapy mostly involved flap surgery, which takes month to heal completely. The evaluation period in our study (1 week and 1 month post operatively) might fall in the initial healing period and also during this the patient might be cautious and protective about their periodontium, because of their recent surgery and strict postoperative instructions that was given to them. Therefore, considering the above factors, during the evaluation, the subjects might be subconsciously limiting their masticatory or chewing force resulting in the reduced values.

Some of the limitations of this study are small sample size and shorter period of evaluation. Thus, future studies should include larger sample size with longer follow-up duration and inclusion of more parameters to standardise the study. Another limitation would be usage of chewing gum which is not very much reliable and accurate in order to assess the masticatory efficacy when compared to methods such as force measuring devices, sieves system, colorimetric method, image analysis, etc.

\section{CONCLUSIONS}

Within the limitations of the study, we conclude that the masticatory efficacy of patients with periodontitis i.e. those with reduced periodontal tissue support is reduced and did not improve even after periodontal therapy.

\section{REFERENCES}

[1] "Mastication" Biology dictionary. https://biologydictionary.net/organ/ (Accessed on October 2019).

[2] Chewing. https://en.wikipedia.org/wiki/Chewing (Accessed on October 2019).

[3] Westberg KG, Kolta A. The trigeminal circuits responsible for chewing. International Review of Neurobiology 2011;97:77-98.

[4] Oliveira NM, Shaddox LM, Toda C, et al. Methods for evaluation of masticatory efficiency in conventional complete denture wearers: a systematized review. Oral Health and Dental Management 2014;13(3):757-62.

[5] Manly RS, Braley LC. Masticatory performance and efficiency. Journal of Dentistry Research 1950;29(4):448-62.

[6] Kleinfelder JW, Ludwigt K. Maximal bite force in patients with reduced periodontal tissue support with and without splinting. J Periodontol 2002;73(10):1184-7.

[7] Yurkstas A, Manly RS. Measurement of occlusal contact area effective in mastication. Am J Orthod 1949;35(3):185-95.

[8] Julien KC, Buschang PH, Throckmorton GS, et al. Normal masticatory performance in young adults and children. Archs Oral Biol 1996;41(1):69-75.

[9] Lambrecht JR. The influence of occlusal contact area on chewing performance. J Prosthet Dent 1965;15(3):44450.

[10] Wilding RJ. The association between chewing efficiency and occlusal contact area in man. Archs Oral Biol 1993;38(7):589-96.

[11] Akeel R, Nilner M, Nilner K. Masticatory efficiency in individuals with natural dentition. Swed Dent J 1992;16(5):191-8.

[12] Gavião MBD, Raymundo VG, Rentes AM. Masticatory performance and bite force in children with primary dentition. Brazilian Oral Research 2007;21(2):146-52.

[13] Van Der Bilt A, Olthoff LW, Bosnian F, et al. Chewing performance before and after rehabilitation of postcanine teeth in man. J Dent Res 1994;73(11):1677-83.

[14] Omar SM, McEwen JD, Ogston SA. A test for occlusal function. The value of a masticatory efficiency test in the assessment of occlusal function. $\mathrm{Br} \mathrm{J}$ Orthod 1987;14(2):85-90.

[15] Luke DA, Lucas PW. Chewing efficiency in relation to occlusal and other variations in the natural human dentition. Br Dent J 1985;159(12):401-3.

[16] Koc D, Dogan A, Bek B. Bite force and influential factors on bite force measurements: a literature review. Eur J Dent 2010;4(2):223-32.

[17] Hannam AG. Periodontal mechanoreceptors. In: Anderson DJ, Matthews B, eds. Mastication. Bristol, UK: John Wright \& Sons Ltd., 1976: p. 23-65. 
[18] Takeuchi N, Yamamoto T. Correlation between periodontal status and biting force in patients with chronic periodontitis during the maintenance phase of theraphy. J Clin Periodontol 2008;35(3):215-20.

[19] Thamaraiselvan M, Elavarasu S, Thangakumaran S, et al. Comparative clinical evaluation of coronally advanced flap with or without platelet rich fibrin membrane in the treatment of isolated gingival recession. Journal of Indian Society of Periodontology 2015;19(1):66-71.
[20] Wu CP, Tu YK, Lu SL, et al. Quantitative analysis of Miller mobility index for the diagnosis of moderate to severe periodontitis - a cross-sectional study. J Dent Sci 2018;13(1):43-7.

[21] Laurell L, Lundgren D. Periodontal ligament areas and occlusal forces in dentitions restored with cross-arch bilateral end abutment bridges. J Clin Periodontol 1985;12(10):850-60. 